\title{
Water sensitivity of sandstones containing swelling and non-swelling clays
}

\author{
K. Krishna Mohan ${ }^{\mathrm{a}}$, Ravimadhav N. Vaidya ${ }^{\mathrm{b}}$, Marion G. Reed ${ }^{\mathrm{c}}$ and H. Scott Fogler \\ ${ }^{a}$ Department of Chemical Engineering, The University of Michigan, Ann Arbor, MI 48109, USA \\ ${ }^{\mathrm{b}}$ Mobil R\&D Corporation, 13777 Midway Rd, Dallas, TX 75244, USA \\ ${ }^{c}$ Chevron Oil Field Research Company, P.O. Box 446, La Habra, CA 90633, USA
}

(Received 28 August 1992; accepted 18 February 1993)

\begin{abstract}
The study presented here focuses on the phenomenon of water sensitivity of sandstones containing swelling and nonswelling clays. This paper describes results of an ongoing investigation on the mechanisms of permeability reduction in sandstones containing swelling and non-swelling clays. These studies show that the critical salt concentrations of sodium chloride and potassium chloride needed to prevent loss of permeability in sandstones containing swelling clay (Stevens sandstone) are considerably higher than the corresponding values for Berea sandstone. A critical salt concentration of calcium chloride is shown to exist for these sandstones. As opposed to Berea sandstone, $\mathrm{pH}$ control may not be sufficient to eliminate loss of permeability in swelling clay sandstones. The results show that crystalline swelling of smectites/mixed layer clays induces significant permeability reduction in the swelling clay sandstones considered in this paper.
\end{abstract}

Keywords: Clay swelling; fines migration; formation damage; water sensitivity.

\section{Introduction}

The permeability or hydraulic conductivity of natural porous media is of primary importance in several areas such as oil production, landfill remediation and soil infiltration. Most oil- and gasproducing formations contain clay minerals that were originally deposited during sedimentation (detrital clay), or precipitated from fluids flowing through the matrix (authigenic clay). Authigenic and detrital clays can cause loss of permeability by several mechanisms. While this loss of permeability is undesirable in the area of oil/gas production it is very beneficial for minimizing leakoff and migration of contaminants in landfill sites.

Correspondence to: H.S. Fogler, Department of Chemical Engineering. The University of Michigan, Ann Arbor, MI 48109, USA.
This loss of permeability is commonly referred to as formation damage in the petroleum industry and is related to the ionic composition and $\mathrm{pH}$ of the permeating fluids when caused by clays. The dependence of permeability on the composition of the flowing aqueous fluids is known as water sensitivity. Prevention of formation damage is essential for the successful economic operation of oil and gas wells.

This paper describes the ongoing studies on the mechanisms of permeability reduction in sandstones containing swelling and non-swelling clays. A number of studies in the past have addressed the subject of formation damage due to nonswelling clays [1-7]. Previous research in our laboratory has elucidated the phenomenon of water sensitivity of Berea sandstone which contains mainly non-swelling clays [5-7]. Their comprehensive study demonstrated the role of $\mathrm{pH}$, ion 
exchange, and brine concentration on the release or detachment of migrating clays from pore surfaces and subsequent permeability loss of the porous medium. Natural formations contain both swelling and non-swelling clays and the clayrelated permeability loss due to foreign fluids in these formations can be attributed to more than one mechanism. In spite of the abundance of swelling clays in sandstones, relatively few studies have been devoted to address the issue of permeability reduction caused by swelling clays $[8,9]$. In the soil science literature, a number of studies on swelling-related permeability loss have been performed using packed columns containing synthetic mixtures of sand and clay [10-17]. There is some concern whether sand-clay mixtures provide a realistic representation of the clays in their natural state [15]. This problem becomes particularly relevant for consolidated sandstones containing swelling clays.

Formation damage duc to clays can be classified as that caused by swelling clays and non-swelling clays. Smectites and mixed layer clays can swell with changing ionic conditions and eventually disperse and migrate with the flowing fluid. Swelling alone reduces the effective area for flow and causes reduction in permeability. Kaolinites and illites are non-swelling clays that tend to detach from the rock surface and migrate when the colloidal conditions are conducive for release. The migrating particles can get trapped in pore throats, thus causing a reduction in permeability. It has been shown the clay composition as well as distribution play an important role in determining whether formation damage problems will be observed in a certain reservoir [18]. Another mechanism of permeability reduction due to clays is an indirect effect caused by the swelling. The depositionary environment could be such that when the clay particles swell, they cause the breakage of fines that are in contact with them. This mechanism is called swelling-induced migration. The three possible mechanisms of permeability reduction in sandstones containing swelling and non-swelling clays are shown schematically in Fig. 1.

Currently, no systematic scientific study of clay-

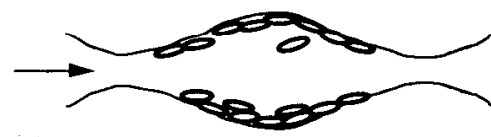

(a)
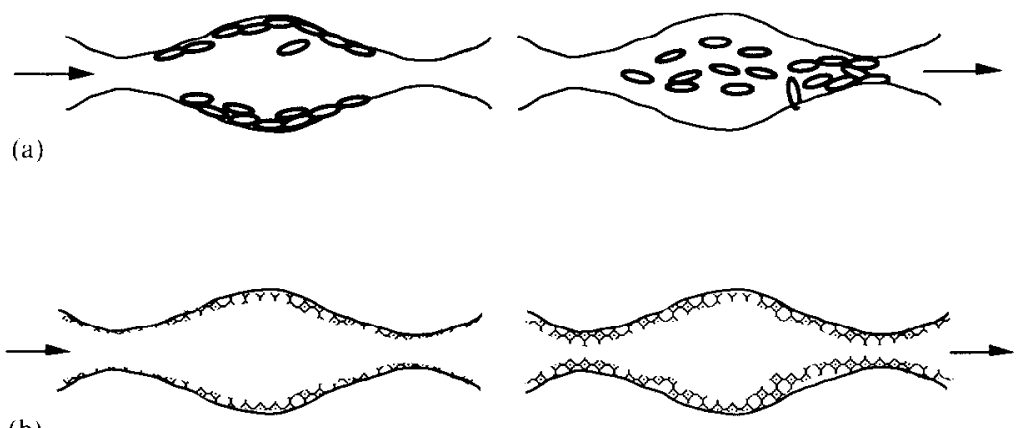

(b)
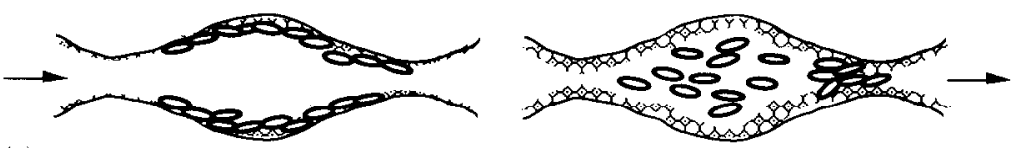

(c)

Fig. 1. Mechanisms of permeability reduction caused by clays in porous media. (a) Migration: changing ionic conditions cause the release of clays from pore walls and result in pore blockage. (b) Swelling: changing ionic conditions cause swelling of clays lining the pores and reduce cross-sectional area for flow. (c) Swelling-induced migration: changing ionic conditions cause swelling of clays lining the pore walls and dislodge fines in the process. 
related formation damage mechanisms in a porous medium containing swelling and non-swelling clays is available in the literature. In view of the importance of this problem, a systematic study to investigate the damage mechanisms operative in a sandstone containing swelling and non-swelling clays was initiated. The goals of this project are to identify the principal causes of damage (reduction in permeability) in sandstones containing swelling and non-swelling clays due to changes in aqueous chemistry and develop an understanding of the relative contributions of swelling and non-swelling clays to the total damage. The objective of this paper is to delineate the mechanisms of permeability reduction in reservoir sandstones due to changes in aqueous composition. A mathematical framework for describing the same will be the subject of a future paper.

In the petroleum industry, such a study will be useful in designing drilling and completion fluids, selecting flood waters, steam feed waters, and in developing clay stabilizers. The results of this study can be applied to other key areas as well. For example, one application is an understanding of the fate of toxic organics which is affected by migrating colloids [19]. Owing to their high surface areas and charge, clays present in the ground contribute significantly to contaminant retention and movement. In addition, results from this study can also be applied to regeneration of filter beds and erosion of earthen embankments [20], and infiltration characteristics of clayey soils [10-13].

\section{Experimental}

\section{Materials}

The experiments in this investigation were conducted on sandstone cores containing swelling and non-swelling clays. These cores were actual field samples supplied by the Department of Energy and Chevron USA. These cores are from the Stevens Sands in Elk Hills Field, CA. The mineralogical composition of these is shown in Table 1. The samples from the depth of $7039 \mathrm{ft}$ contain a high proportion of swelling and non-swelling clays. The mineralogical composition of Berea sandstone is also shown for comparison. All the chemicals used in the flow experiments were reagent grade.

\section{Experimental set-up}

A schematic of the experimental set-up is shown in Fig. 2. It consists of a Beckman HPLC pump for fluid injection, a Hassler cell in which the core is contained, flow-through electrodes for monitoring $\mathrm{pH}$ and conductivity, digital pressuremeasuring devices and a data acquisition system interfaced to an IBM personal computer.

\section{Procedure}

The following procedure was usually adopted for experiments. Cores were supplied to our laboratory by Chevron Oil Field Research Company after cleaning them miscibly with toluene and methanol to displace any hydrocarbons, salts and water in the cores and then re-saturated with $1 \mathrm{~N}$ $\mathrm{NaCl}$. Typically, these cores were vacuum saturated in the brine for a certain experiment and placed in the core holder. The permeating fluid is injected at a constant rate through a $0.22 \mu \mathrm{m}$ inline filter and the pressure drop across the length of the core is monitored. The permeability of the core was calculated using the measured pressure drop in Darcy's law.

All the permeability measurements are normalized with respect to the initial permeability of the core to the saturating fluid.

The following experiments were designed to estimate the maximum possiblc damage and the relative contributions of the various clays to the damage.

(i) Water shock experiments involve flowing a high concentration of a salt solution and then switching the flow to deionized water. These types of experiments are designed to estimate the maximum possible damage because swelling clays and non-swelling clays are expected to disperse and migrate under these conditions. 
TABLE I

Mineralogical composition of Stevens sandstones and Berea sandstone

\begin{tabular}{|c|c|c|c|}
\hline Mineral & Berea sandstone $[22]$ & $\begin{array}{l}\text { Stevens sandstone } \\
\text { (depth } 7039 \mathrm{ft} \text { ) }\end{array}$ & $\begin{array}{l}\text { Stevens sandstone } \\
\text { (Depth } 7352.17 \mathrm{ft} \text { ) }\end{array}$ \\
\hline Quartz & 86 & 35 & 32 \\
\hline $\mathrm{K}$-feldspars & 5 & 18 & 17 \\
\hline Plagioclase & & 34 & 39 \\
\hline Calcite & 1 & 1 & 1 \\
\hline Dolomite & 1 & 1 & 0 \\
\hline Siderite & & 3 & 2 \\
\hline Clays & 7 & 8 & 9 \\
\hline Total & 100 & 100 & 100 \\
\hline $\begin{array}{l}\mathrm{CEC} \\
\text { (mequiv per } 100 \mathrm{~g} \text { ) }\end{array}$ & $0.5-2.0$ & 2.9 & 4.2 \\
\hline Total clays ( wt \%) & $5-8$ & 8 & 9 \\
\hline Kaolinite & 90 & 25 & 9 \\
\hline Illite & 9 & 30 & 19 \\
\hline Smectite & Traces & 29 & 29 \\
\hline Mixed layer & Traces & 13 & 28 \\
\hline Chlorite & Traces & 3 & 15 \\
\hline Porosity & $0.19-0.20$ & 0.18 & 0.20 \\
\hline $\begin{array}{l}\text { Initial permeability } \\
\text { (Brine) }\end{array}$ & $>100 \mathrm{mD}$ & $<10 \mathrm{mD}$ & $<10 \mathrm{mD}$ \\
\hline
\end{tabular}

${ }^{a}$ Mineralogical analysis provided by Chevron Oil Field Research Company.

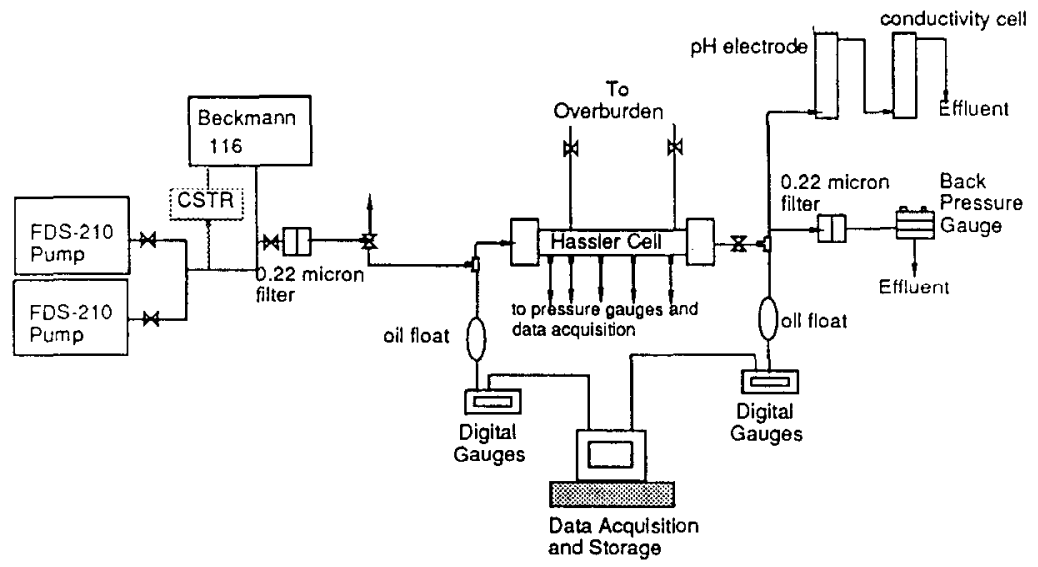

Fig. 2. Experimental set-up used in water sensitivity studies [7].

(ii) Critical salt concentration experiments involve reducing the salt concentration in steps and measuring the permeability. The concentration at which the initial reduction in permeability is noted is known as the critical salt concentration.
The existence of critical salt concentration theoretically and experimentally for Berea sandstone which contains primarily kaolinite has been established [5]. The critical salt concentration is analogous to the critical flocculation concentration for clays in 
the DLVO theory [21] and depends on the type of cation and the $\mathrm{pH}$.

(iii) Gradual salinity decrease experiments in which the salt concentration is decreased in a gradual manner using a continuous stirred tank reactor (CSTR) fed with deionized water as the reservoir for the fluid. These experiments were designed to test if the rate of salinity decrease has any effect on the permeability change.

(iv) In step change $\mathrm{pH}$ type of experiments the salinity was decreased to zero at a low $\mathrm{pH}$ and then the $\mathrm{pH}$ was increased in steps. The purpose of this set of experiments was to study the effect of $\mathrm{pH}$ on the damage.

(v) Cation-specific experiments involved saturating the core with chloride solution of a certain cation and switching to a different cation at the same ionic concentration. These experiments were designed to study the effect of cation hydration on the damage of Stevens sandstones.

The results obtained are summarized by the type of the experiment in the following sections.

\section{Results}

\section{Water shock}

The results of water shock (abrupt change in salinity) experiments using cores saturated with sodium chloride are shown in Table 2 . The permeability response and effluent $\mathrm{pH}$ in a typical water

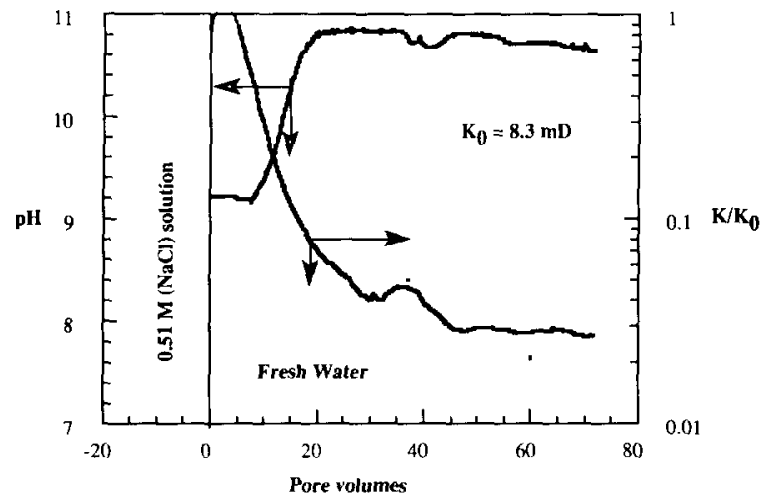

Fig. 3. Permeability response and effluent $\mathrm{pH}$ during water shock (abrupt reduction in salinity) of Stevens sandstone saturated with $0.5 \mathrm{M}$ sodium chloride.

shock experiment are shown in Fig. 3. The results show that these cores get damaged substantially by water shocking. The effluent $\mathrm{pH}$ reaches a maximum of about 10.6 in all the experiments. This increase in $\mathrm{pH}$ is due to exchange of hydrogen ions in water with adsorbed sodium ions. Although the damage is quite significant, it is not as drastic as that observed in Berea sandstone [5] which has a higher initial permeability $(163-500 \mathrm{mD})$ and contains primarily kaolinite, a non-swelling clay. Once the damage is initiated, it occurs very rapidly in Berea sandstone compared to Stevens sandstone.

The non-swelling clay content in Stevens sandstone $(4.5 \%)$ is comparable to the kaolinite content in Berea sandstone (5-8\%) [22]. The fact that the damage in Stevens sandstone is an order of magni-

TABLE 2

Water shock of Stevens sandstone cores saturated with sodium chloride

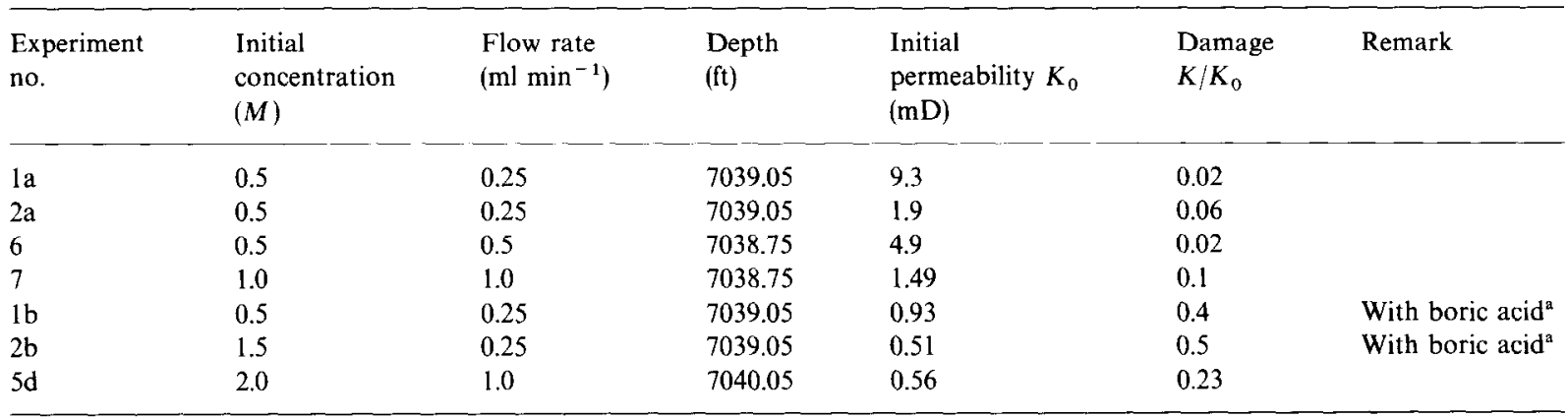

${ }^{a}$ Boric acid is used to buffer the flowing solutions. 
TABLE 3

Water shock of Stevens sandstone cores saturated with potassium chloride

\begin{tabular}{llllll}
$\begin{array}{l}\text { Experiment } \\
\text { no. }\end{array}$ & $\begin{array}{l}\text { Initial } \\
\text { concentration } \\
(M)\end{array}$ & $\begin{array}{l}\text { Flow rate } \\
\left.(\mathrm{ml} \mathrm{min})^{-1}\right)\end{array}$ & $\begin{array}{l}\text { Depth } \\
(\mathrm{ft})\end{array}$ & $\begin{array}{l}\text { Initial } \\
\text { permeability } K_{0} \\
(\mathrm{mD})\end{array}$ & $\begin{array}{l}\text { Damage } \\
K / K_{0}\end{array}$ \\
\hline 17 & 1.0 & 1.0 & 7041.00 & 4.82 & 0.62 \\
20 & 2.0 & 1.0 & 7040.00 & 0.91 & 0.60 \\
51 & 2.0 & 1.0 & 7352.25 & 0.72 & 0.72 \\
\hline
\end{tabular}

tude lower than in Berea sandstone even though the non-swelling clay content is comparable, implies that the non-swelling clays may not be primarily responsible for the observed damage during water shock of Stevens sandstones. It has been shown that buffering the deionized water to prevent a $\mathrm{pH}$ increase prevents damage in Berea sandstone [7]. Similar experiments conducted on Stevens sandstone show that (Table 2) the buffering action reduces the damage but does not eliminate it completely.

Results of water shock experiments on cores saturated with potassium chloride are shown in Table 3. These runs show that the damage is not very high compared to experiments where sodium is the sensitizing ion (cation saturating the sandstone before injecting deionized water). In Berea sandstone, water shock with potassium as the sensitizing ion results in damage which is an order of magnitude less than that when sodium is the sensitizing ion [5]. Thus, potassium is less damaging to non-swelling clays than sodium. X-ray diffraction (XRD) measurements on montmorillonitcs [23] have shown that basal spacing of potassium montmorillonite does not increase beyond 15 $\AA$ in distilled water. In comparison, sodium montmorillonite can swell to $120 \AA$ in distilled water. Thus, for both swelling and non-swelling clays, potassium is less sensitizing than sodium. Hence, water shocking a Stevens sandstone following saturation with potassium chloride should not result in as high damage as with sodium. The experiments show that potassium is indeed much less sensitizing than sodium.

The results of water shock experiments on cores saturated with calcium chloride are summarized in Table 4. In these experiments, cores obtained from the same depth showed variation in the results (see experiments 13-15), especially the degrec and the time required for damage. The damage was between $25-60 \%$ of the original permeability and sometimes occurred over 200 pore volumes. However, cores from a depth of $7352 \mathrm{ft}$ showed consistent and reproducible trends.

TABLE 4

Water shock of Stevens sandstone cores salurated with calcium chloride

\begin{tabular}{lllllll}
$\begin{array}{l}\text { Experiment } \\
\text { no. }\end{array}$ & $\begin{array}{l}\text { Initial } \\
\text { concentration } \\
(M)\end{array}$ & $\begin{array}{l}\text { Flow rate } \\
\left(\mathrm{ml} \mathrm{min} \mathrm{mi}^{-1}\right)\end{array}$ & $\begin{array}{l}\text { Depth } \\
(\mathrm{ft})\end{array}$ & $\begin{array}{l}\text { Initial } \\
\text { permeability } K_{0} \\
(\mathrm{mD})\end{array}$ & $\begin{array}{l}\text { Damage } \\
K / K_{0}\end{array}$ & $\begin{array}{l}\text { Remark } \\
\text { (Pore volumes for damage) }\end{array}$ \\
\hline 16 & 0.5 & 1.0 & 7041.00 & 1.7 & 0.85 & About $40 \mathrm{PV}$ \\
13 & 0.5 & 1.0 & 7039.60 & 0.65 & 0.44 & $200 \mathrm{PV}$ \\
52 & 0.5 & 1.0 & 7352.17 & 1.43 & 0.9 & $700 \mathrm{PV}$ \\
53 & 0.5 & 1.0 & 7352.17 & 0.64 & 0.85 & $700 \mathrm{PV}$ \\
14 & 0.5 & 1.0 & 7303.60 & 4.70 & 0.75 & $40 \mathrm{PV}$ \\
15 & 0.5 & 1.0 & 7303.60 & 2.23 & 0.41 & $400 \mathrm{PV}$ \\
\hline
\end{tabular}


The results of water shock of calcium chloride saturated Stevens sandstone cores differ from those observed in Berea sandstone. It has been reported that water shock of a calcium chloride saturated Berea sandstone does not result in any damage $[5,6]$. Since the water shock of calcium saturated cores cannot mobilize the non-swelling clays, the damage has to be attributed to that caused by swelling clays. The damage observed during water shock of Stevens sandstones saturated with calcium chloride cores can be attributed to swelling or swelling-induced migration. XRD analysis performed on Ca-montmorillonite [23] showed that the basal spacing increases to $18.9 \AA$ in deionized water. This value is higher than the basal spacing for potassium saturated montmorillonite in deionized water (15 $\AA$ ) [23]. Consequently, cores which can exhibit damage due to water shock with potassium will exhibit damage during water shock following calcium.

In summary, the water shock experiments show that Stevens sandstone cores are water sensitive. These cores exhibit permeability reduction due to water shock following saturation with sodium chloride, potassium chloride and calcium chloride solutions. Water shock of sodium chloride saturated cores causes the most damage. In some cases, water shock of calcium chloride saturated cores causes more damage than potassium chloride saturated cores. The results of water shock experiments suggest that the swelling clays contribute significantly to the total damage.

\section{Critical salt concentration}

The critical salt concentration is defined as the concentration of the flowing solution above which there will be no damage due to changes in salt concentration. This concentration provides a useful estimate of the salinity required to minimize damage in reservoirs. The existence of a critical salt concentration for Berea sandstone has been established [5]. The permeability reduction in Berea sandstone is governed by the detachment of clay particles from the surface which are subse- quently captured in narrow pore throats. The detachment is dictated by the balance of the van der Waals attractive forces and electrostatic repulsive forces between the surface and the clay particles. The concentration of salt solution and $\mathrm{pH}$ affect the range of influence of the repulsive forces. The surface potential of kaolinites is influenced by type of cation and the $\mathrm{pH}$, causing the critical salt concentration values of sodium, potassium and calcium to be different. Since the phenomenon of water shock has been shown to exist for Stevens sandstone, it follows that there will be a critical salt concentration above which there can be no damage. A set of experiments was conducted to determine the critical salt concentration of sodium chloride, potassium chloride and calcium chloride.

The results of the critical salt concentration (CSC) experiments conducted with sodium chloride are shown in Table 5. The results of experiment 9a are shown in Fig. 4. These experiments show that the critical salt concentration of sodium chloride needed to prevent damage is between $0.4-0.5 \mathrm{M}$ which is much higher than the corresponding value for Berea sandstone $(0.07 \mathrm{M})$ [5]. If it is assumed that the critical salt concentration needed to detach kaolinites in Berea and Stevens sandstones are similar, the critical salt concentration of $0.4-0.5 \mathrm{M}$ for Stevens sandstones should be attributed to clay swelling mechanisms.

The swelling behavior of smectites depends on the total layer charge, distribution of layer charge

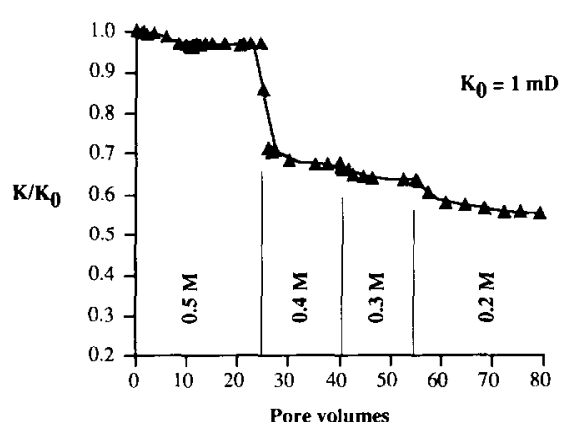

Fig. 4. Permeability reduction of Stevens sandstone during determination of critical salt concentration (CSC) of sodium chloride. 
TABLE 5

CSC experiments with sodium chloride on Stevens sandstone cores

\begin{tabular}{llllllll}
\hline $\begin{array}{l}\text { Experiment } \\
\text { no. }\end{array}$ & $\begin{array}{l}\text { Initial } \\
\text { concentration } \\
(M)\end{array}$ & $\begin{array}{l}\text { Flow rate } \\
\left(\mathrm{ml} \mathrm{min} \mathrm{min}^{-1}\right)\end{array}$ & $\begin{array}{l}\text { Depth } \\
(\mathrm{ft})\end{array}$ & $\begin{array}{l}\text { Initial } \\
\text { permeability } K_{0} \\
(\mathrm{mD})\end{array}$ & $\begin{array}{l}\text { Final } \\
\text { damage } \\
K / K_{0}{ }^{\mathrm{a}}\end{array}$ & $\begin{array}{l}\text { CSC } \\
(M)\end{array}$ & $\begin{array}{l}\text { Damage at } \\
\mathrm{CSC} \\
K / K_{0}\end{array}$ \\
\hline 3 & 0.5 & 0.25 & 7039.05 & 2.50 & 0.045 & $0.5-0.25$ \\
4 & 2.0 & 0.50 & 7039.05 & 1.90 & $<0.055$ & $0.5-0.25$ \\
$9 \mathrm{a}$ & 1.0 & 0.50 & 7040.50 & 1.00 & 0.47 & $0.5-0.25$ & 0.65 \\
\hline
\end{tabular}

${ }^{a}$ Final damage refers to permeability reduction after flow of deionized water.

and the type of interlayer cations $[24,25]$. Sodium saturated smectites of high layer charge do not swell and disperse even in deionized water [24]. For smectites which are typically not in the high end of the layer charge, the swelling is distinguished by two regimes, namely crystalline and osmotic. At high concentration $(2.5 \mathrm{~m})$ of sodium chloride the layers are separated by $15.4 \AA$ [24]. This spacing corresponds to two monolayers of water between clay layers. As the concentration of sodium chloride is decreased, the basal spacing increases to $18.5 \AA$ in a discrete manner corresponding to the addition of a third layer of water between the two clay layers. The transition from 15.5 to $18.5 \AA$ occurs at different concentrations for smectites of different layer charge. This regime of increase in basal spacing is termed the crystalline swelling region. As the concentration of sodium chloride is decreased further, the basal spacing jumps to $40 \AA$ and increases linearly with respect to $C^{-0.5}$ [23] where $C$ is the molal concentration of sodium chloride. This region is termed the osmotic swelling regime [24]. The transition between the crystalline and osmotic swclling regions occurs between 0.5 and $0.25 \mathrm{M}$. This transition from crystalline osmotic region of swelling is dictated by the total layer charge of the smectites and that contributed by the tetrahedral layers. The total layer charge and the charge distribution of the smectites and mixed layer clays in Stevens sandstone is not known at present. Since we know the core damages during water shock and this damage cannot be eliminated with buffering, we can assume that the smectites or mixed layer clays responsible for the damage do not have a high layer charge.

From the results presented above and the previous discussion, we infer that the onset of damage may be due to two possibilities: (a) crystalline swelling where the basal spacing may have increased from 15.5 to $18.5 \AA$; (b) transition from crystalline swelling to osmotic swelling region where the particles become dispersed and migrate with flow. In the latter case, it is implicitly assumed that crystalline swelling preceding the transition to osmotic regime does not cause significant changes in permeability. The critical salt concentration corresponds to the concentration at which either of these transitions occur for the smectites/mixed layer clays in Stevens sandstone.

The critical salt concentration experiments with potassium chloride and calcium chloride are summarized in Table 6 . The critical salt concentration of potassium chloride needed to prevent damage is in the range of $0.2-0.3 \mathrm{M}$ at $\mathrm{pH}$ of 8.0 . This value is again much higher than the corresponding value for Berea $(0.03 \mathrm{M})$. The critical salt concentration of calcium chloride needed to prevent damage in Stevens sandstone is between 0.2 and $0.3 \mathrm{M}$. The permeability reduction observed in dilute calcium chloride solutions again gives support to the hypothesis that crystalline swelling causing permeability reduction because smectites are known to exhibit crystalline swelling in calcium chloride solutions [26]. Unlike sodium saturated smectites, calcium saturated smectites do not exhibit osmotic swelling. Thus the damage 
TABLE 6

CSC experiments with potassium chloride and calcium chloride on Stevens sandstone cores

\begin{tabular}{lllllll}
\hline $\begin{array}{l}\text { Experiment } \\
\text { no. }\end{array}$ & $\begin{array}{l}\text { Initial } \\
\text { concentration } \\
(M)\end{array}$ & $\begin{array}{l}\text { Flow rate } \\
\left.(\mathrm{ml} \mathrm{min})^{-1}\right)\end{array}$ & $\begin{array}{l}\text { Depth } \\
(\mathrm{ft})\end{array}$ & $\begin{array}{l}\text { Initial } \\
\text { permeability } K_{0} \\
(\mathrm{mD})\end{array}$ & $\begin{array}{l}\text { Final } \\
\text { damage } \\
K / K_{0}{ }^{2}\end{array}$ & $\begin{array}{l}\text { CSC } \\
(M)\end{array}$ \\
\hline 19 & $2.0(\mathrm{KCl})$ & 1.0 & 7040.60 & 4.20 & $<0.55$ & $0.3-0.2$ \\
15 & $0.5\left(\mathrm{CaCl}_{2}\right)$ & 1.0 & 7303.60 & 2.23 & 0.76 & $0.3-0.2$ \\
14 & $0.5\left(\mathrm{CaCl}_{2}\right)$ & 1.0 & 7303.60 & 4.70 & $0.9 \mathrm{I}$ & $<0.05$ \\
\hline
\end{tabular}

${ }^{a}$ Final damage refers to permeability reduction after flow of deionized water.

observed in Stevens sandstones due to calcium can be attributed to crystalline swelling.

In summary, these sets of experiments show that the critical salt concentration of sodium chloride, potassium chloride and calcium chloride needed to prevent damage in Stevens sandstone is higher than the characteristic values of Berea. The onset of damage may be attributed to crystalline swelling of the swelling clays in the sandstone or the transition from crystalline swelling to osmotic swelling regime.

\section{Experiments with $\mathrm{pH}$ control}

The water shock experiments have demonstrated that the Stevens sandstones are water sensitive and the critical salt concentration experiments have shown that the onset of damage in these sandstones can be attributed to swelling clays. The Stevens sandstone contains a mixture of swelling (smectite, mixed layer) and non-swelling (kaolinite, illite) clays. If the damage due to non-swelling clays can be eliminated completely, the contribution of swelling clays to the total damage can be ascertained. The rate of salinity decreases experiments and $\mathrm{pH}$ experiments were designed to achieve this objective.

It has been shown that the rate of salinity change plays a critical role in determining the extent of damage in Berea sandstone [1,5]. The permeability decreases markedly when the salt concentration is reduced in a rapid manner compared to a slow procedure. The underlying process that governs this phenomenon is the exchange of hydrogen ions with the adsorbed sodium ions. When the concen- tration is decreased, a $\mathrm{pH}$ transient is set up in the core. Rapid reduction of salinity causes the transient to be a sharp wave with the peak attaining high values of $\mathrm{pH}(10.5)$ for injection of deionized water at neutral $\mathrm{pH}$. This $\mathrm{pH}$ increase causes the kaolinites to develop sufficiently high potentials to cause them to detach from the surface, migrate and be captured in the pore constrictions. If the salt concentration is reduced gradually, the transient becomes broad and the $\mathrm{pH}$ never becomes high enough for kaolinites to attain sufficiently high negative potentials [7]. Another method of maintaining low potentials on kaolinites is to reduce the injection $\mathrm{pH}$. In such a case, even an abrupt decrease in salinity does not raise the $\mathrm{pH}$ high enough to increase the potentials substantially.

The results of gradual salinity decrease experiments on Stevens sandstone are summarized in Table 7. A typical result is shown in Fig. 5 The gradual decrease in salinity does reduce the maxi-

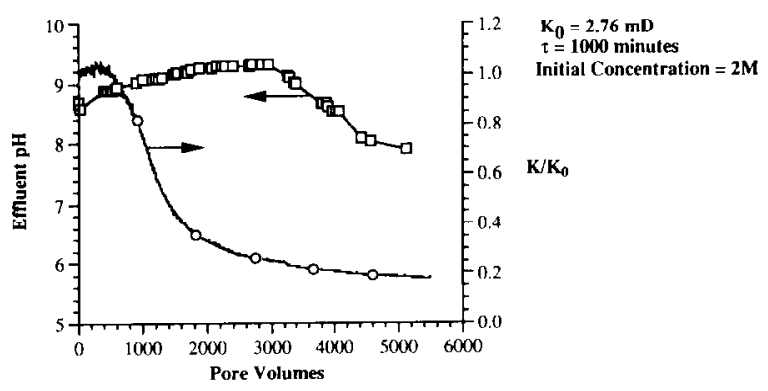

Fig. 5. Permeability reduction of Stevens sandstone during gradual decrease in salinity $\left(C=C_{0} \mathrm{e}^{-t / \tau}\right)$ where $C$ is the injected salt concentration at time $t, C_{0}$ is the injected salt concentration at $t=0$, and $\tau$ is a constant that determines the rate of decrease. 
TABLE 7

Gradual salinity decrease experiments with sodium chloride on Stevens sandstone cores

\begin{tabular}{lllllll}
\hline $\begin{array}{l}\text { Experiment } \\
\text { no. }\end{array}$ & $\begin{array}{l}\text { Initial } \\
\text { concentration } \\
(M)\end{array}$ & $\begin{array}{l}\text { Flow rate } \\
\left.(\mathrm{ml} \mathrm{min})^{-1}\right)\end{array}$ & $\begin{array}{l}\text { Depth } \\
(\mathrm{ft})\end{array}$ & $\begin{array}{l}\text { Initial } \\
\text { permeability } K_{0} \\
(\mathrm{mD})\end{array}$ & $\begin{array}{l}\text { Damage } \\
K_{0} K_{0}\end{array}$ & $\begin{array}{l}\tau^{\mathrm{a}} \\
(\mathrm{min})\end{array}$ \\
\hline 4 & 2.0 & 0.5 & 7039.05 & 1.9 & 0.05 & $113.6^{\mathrm{b}}$ \\
$8 \mathrm{a}$ & 0.5 & 1.0 & 7038.75 & 1.58 & 0.15 & 400 \\
$5 \mathrm{~b}$ & 2.0 & 1.0 & 7040.50 & 1.70 & 0.28 & 1000 \\
26 & 2.0 & 1.0 & 7039.35 & 2.76 & 0.18 & 1000 \\
\hline
\end{tabular}

${ }^{a}$ The inlet concentration in a gradual salinity decrease experiment changes as $C=C_{0} \mathrm{e}^{-t / \tau}$ where $C_{0}$ is the initial concentration.

${ }^{b}$ Experiment 4 is a step decrease in salinity. The changes in concentration are such that they can be represented by a gradual salinity decrease experiment with a residence time of 113.6 min.

mum effluent $\mathrm{pH}$ observed. However, the final permeability was fivefold lower than the original permeability. Thus, even though the salinity change was conducted in such a way that the $\mathrm{pH}$ increase is minimized, significant damage was observed. Since gradual salinity decrease eliminates migration of non-swelling clays, this damage can be attributed to swelling clays.

The results of the rate of salinity decrease experiments of Stevens sandstone are compared with the Berea sandstone experiments in Fig. 6. This figure shows the final permeabilities obtained in the sandstones as a function of the rate of salinity change expressed as the space velocity. For Berea sandstone we observe a clear critical rate of salinity decrease above which permeability change is substantial. However, the damage in Stevens sandstone is significant even at a low rate of salinity decrease. The experiments performed on the Stevens sand-

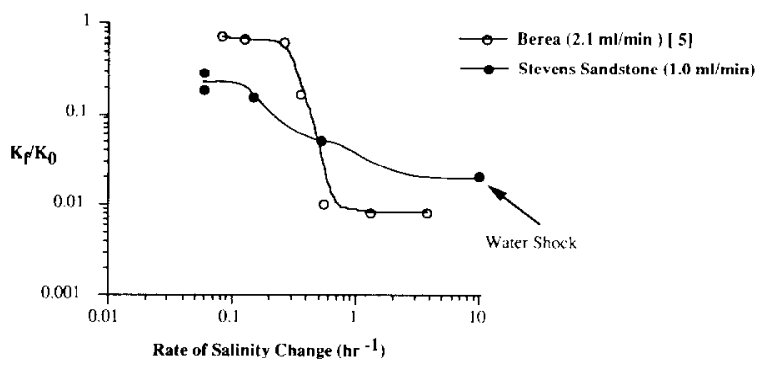

Fig. 6. Comparison of the final permeability reductions obtained in Stevens sandstone and Berea sandstone $\lceil 5\rceil$ as a function of the rate salinity decrease. stone so far have not included any at high rate of salinity change. The last point on this curve corresponds to a water shock, i.c. an infinite rate in change of salinity. The trend in these points indicates that there may not be a critical rate of salinity change for Stevens sandstone demarcating regions of high and low degree of damage.

The results of the experiments in which the injection $\mathrm{pH}$ was controlled are shown in Table 8 and a typical figure is shown in Fig. 7. In these experiments, the core is saturated with high salt concentration, and the concentration of the flowing solution is dropped to $0.0 \mathrm{M}$ at a pH of 2.0 . The $\mathrm{pH}$ of the injected solution is then increased in gradual steps. The figure shows that the majority of the damage in this experiment is observed when the concentration of the solution is reduced to $0.0 \mathrm{M}$ at low $\mathrm{pH}$. This permeability reduction at

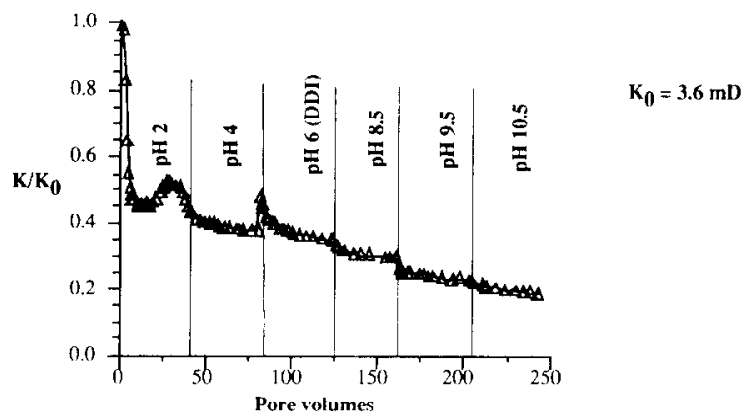

Fig. 7. Permeability reduction of Stevens sandstone during step changes in injection $\mathrm{pH}$ at $0 M$ salinity. (Core was initially saturated in $2 \mathrm{M} \mathrm{NaCl}$.) 
TABLE 8

Experiments with step changes in injection $\mathrm{pH}$ on Stevens sandstone cores

\begin{tabular}{llllll}
\hline $\begin{array}{l}\text { Experiment } \\
\text { no. }\end{array}$ & $\begin{array}{l}\text { Initial } \\
\text { concentration } \\
(M)\end{array}$ & $\begin{array}{l}\text { Flow rate } \\
\left.(\mathrm{ml} \mathrm{min})^{-1}\right)\end{array}$ & $\begin{array}{l}\text { Depth } \\
(\mathrm{ft})\end{array}$ & $\begin{array}{l}\text { Initial } \\
\text { permeability } K_{0} \\
(\mathrm{mD})\end{array}$ & $\begin{array}{l}\text { Damage at pH } \\
2.0^{\mathrm{a}}\end{array}$ \\
\hline $11 \mathrm{a}$ & 2.0 & 1.0 & 7040.50 & 3.60 & 0.50 \\
12 & 2.0 & 0.4 & 7039.60 & 0.39 & 0.57 \\
\hline
\end{tabular}

${ }^{a}$ Permeability reduction due to change in salt concentration.

${ }^{b}$ Final damage refers to permeability reduction after flow of deionized water at $\mathrm{pH} 10.5-11.0$.

low $\mathrm{pH}$ implies that damage due to swelling clays is substantial. As mentioned before, the damage due to kaolinites does not become apparent till high $\mathrm{pH}$ (greater than 9). The critical flocculation concentration of illites at $\mathrm{pH} 6.0$ is $0.025 \mathrm{M}$ [28] and is expected to be lower at pH 2.0. Consequently, the damage observed at $\mathrm{pH} 2.0$ can be attributed to swelling clays. Comparing experiment 12 (Table 8) and experiment $5 \mathrm{~b}$ (Table 7), we observe that the damage is similar. In both these experiments, the damage due to non-swelling clays was suppressed by $\mathrm{pH}$ control. The close agreement between the damage observed in these two experiments provides further proof that the observed damage can be attributed to swelling clays.

Since the effect of rate of salinity decrease and $\mathrm{pH}$ control on the migration of non-swelling clays is known from the Berea sandstone data, the Stevens sandstone data appear to be representative of damage caused by swelling clays. This is particularly true for low rates of salinity change and injection of low $\mathrm{pH}$ solutions, where the damage by non-swelling clays is suppressed. These results raise the issue of the effect of rate of salinity decrease on damage due to swelling alone. As discussed previously, the rate of change of salinity affects the $\mathrm{pH}$ wave that accompanies a salinity change. One would expect the rate of salinity change to affect the damage caused by swelling if the basal spacing of swelling clays is influenced by the $\mathrm{pH}$ of the solution. The total charge on smectites is primarily due to isomorphic substitution and also due to the $\mathrm{Al}-\mathrm{OH}$ groups on the edges [27]. The charge due to isomorphic substitu- tion is independent of the $\mathrm{pH}$ of the solution, but the charge due to the hydroxyl groups is $\mathrm{pH}$ dependent. There is no published data that describe the effect of $\mathrm{pH}$ on the basal spacing of clays. Intuitively, since the $\mathrm{pH}$ affects the charge of the smectite, one would expect $\mathrm{pH}$ to influence the basal spacings. The zeta potential of montmorillonites is known to be a function of $\mathrm{pH}$. It is indeed likely that the $\mathrm{pH}$-dependent charge is much smaller than the charge due to isomorphic substitution which would make the basal spacing measurements independent of $\mathrm{pH}$. On the basis of the permeability measurements in rate-of-salinitydecrease and water-shock experiments, we infer that $\mathrm{pH}$ does not change the basal spacings of the smectites and mixed layer clays in Stevens sandstone significantly.

In summary, the rate of salinity decrease experiments show that there may not be a critical rate above which damage to Stevens sandstones undergoes a clear transition. The damage to swelling clay sandstones at low rate of salinity decrease and injection of low $\mathrm{pH}$ solutions is substantial, indicating that the $\mathrm{pH}$ control may not be the sole factor in eliminating damagc. This fact again lends support to the conclusion that the clay swelling mechanisms contribute significantly to the total damage.

\section{Cation-specific effects}

The experimental results described to this point have clearly shown that swelling clays contribute significantly to the total damage in the Stevens 
sandstones. As described previously, the damage due to swelling clays can be attributed to (a) macroscopic swelling and dispersion of the swelling clays and (b) movement of fines induced by clay swelling. The experiments performed in this section were designed to study whether swelling per se or migration induced by swelling causes the damage. Additionally, these experiments were designed to examine whether the swelling that causes the damage is in the crystalline region or osmotic domain.

The main feature of the crystalline swelling is the strong dependence of this type of swelling on the hydration energy of the interlayer cation [23]. The following experiment was conducted to test if crystalline swelling contributes to the damage in Stevens sandstone. A core saturated with $1 \mathrm{M} \mathrm{KCl}$ was subjected to flow of $0.5 \mathrm{M} \mathrm{KCl}$ and then switched to flow of $0.5 \mathrm{M} \mathrm{NaCl}$. The results of this experiment along with a similar experiment on Berea sandstone are shown in Fig. 8. The permeability of the Stevens sandstone decreased sharply as soon as the flow was switched to sodium chloride. The accompanying result with Berea sandstone shows no such transition. Berea sandstone cannot show any transition because the layers in kaolinites do not exhibit crystalline swelling. This result clearly shows that crystalline swelling contributes to damage in the swelling clay sandstone. In this experiment the permeability loss was approximately $20 \%$.

The hypothesis that crystalline swelling causes significant damage in Stevens sandstone was fur- ther tested by conducting an experiment in which a core was subjected to flow of salt solutions with increasing radius of hydration. For monovalent cations, increase in radius of hydration is equivalent to increasing hydration energy. According to Norrish [23], the hydration energy is the determining factor for crystalline swelling. The results of this experiment are shown in Fig. 9. The experiment shows that during the flow of cesium, ammonium and potassium chloride solutions, the permeability of the core does not change. There is a marginal increase in permeability with potassium chloride. As soon as the flow was switched to sodium chloride, the permeability dropped by $30 \%$. The sodium chloride solution was followed with lithium chloride which has a higher radius of hydration. The permeability of the core dropped to about $40 \%$ of the original value. Flow of calcium chloride and magnesium chloride did not damage the core further even though they have larger radii of hydration. The higher charge of calcium and magnesium ions makes the effective hydration energy per unit charge lower than the values for sodium and lithium, hence $\mathrm{Ca}^{2+}$ and $\mathrm{Mg}^{2+}$ are less effective for swelling. This experiment confirms that crystalline swelling is a major factor in permeability loss of Stevens sandstones.

The results described above establish that crystalline swelling causes damage to Stevens sandstone. However, it does not provide any information on distinguishing the damage due to swelling or swelling-induced movement. Crystalline swelling per se is known to be reversible for
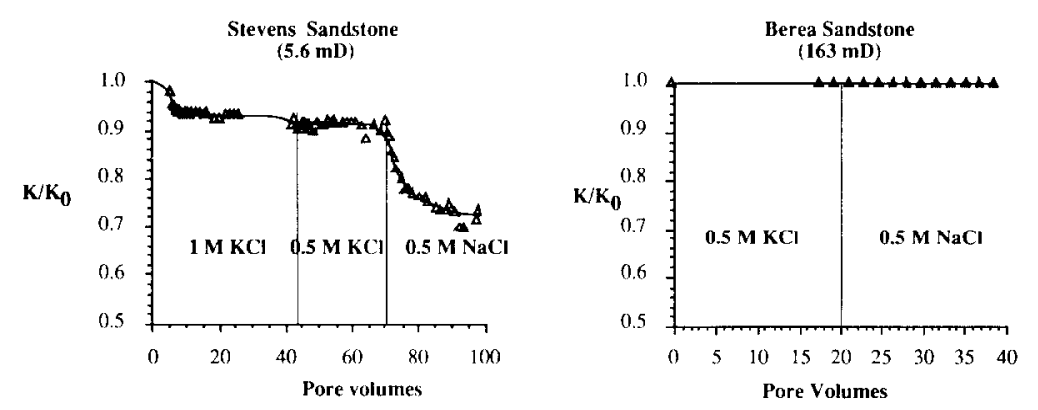

Fig. 8. Cation-specific damage observed in Stevens sandstone at high salt concentration and absent in Berea sandstone. 
$K_{0}=14.68 \mathrm{mD}$

$1 \mathrm{~m}$ solutions
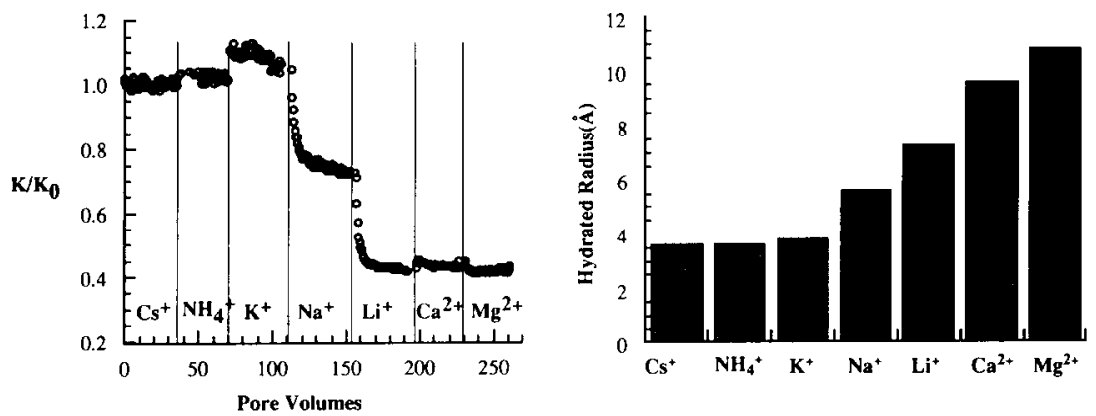

Fig. 9. Permeability response of Stevens sandstone subjected to flow of solutions containing cations of increasing radius of hydration at 1 molal. Hydrated radii were obtained from Ref. [38].

smectites of low layer charge [25]. This reversibility or lack of hysteresis is due to the fact that the layers do not expand substantially to undergo irreversible conformational changes. Since the movement of layers does not exceed 5-6 $\AA$, the basal spacing can regain its original value by reverting back to a solution of lower hydration radius. Thus, if the permeability loss was strictly due to swelling, changing to the original solution should regain the permcability. If the damage is due to swelling-induced migration, switching back to the original solution will not make the core regain its permeability. The core used in the experiment shown in Fig. 9 was used to test this hypothesis. The results of this experiment are shown in Fig. 10. On switching to solutions of smaller hydration energy or radius of hydration, the permeability increased marginally. This result clearly demon- strates that the damage in this core was strictly due to swelling-induced migration.

An additional factor that affects the basal spacing in the crystalline swelling regime is the concentration of the salt. Further proof that the damage caused by swelling-induced movement may be attributed to crystalline swelling can be obtained by performing an experiment similar to that in Fig. 9 at different concentrations. In these experiments, a core was saturated with 2 molal cesium chloride solution, and the experiment (similar to Fig. 9) was repeated. The results of such experiments are shown in Figs 11-13. At a concentration of 2 molal, switching of potassium to sodium does not cause damage and switching to lithium causes marginal damage. At $1 M$, the results obtained in Fig. 9 are reproduced. At a concentration of $0.5 \mathrm{M}$, switching from potassium to sodium caused slight

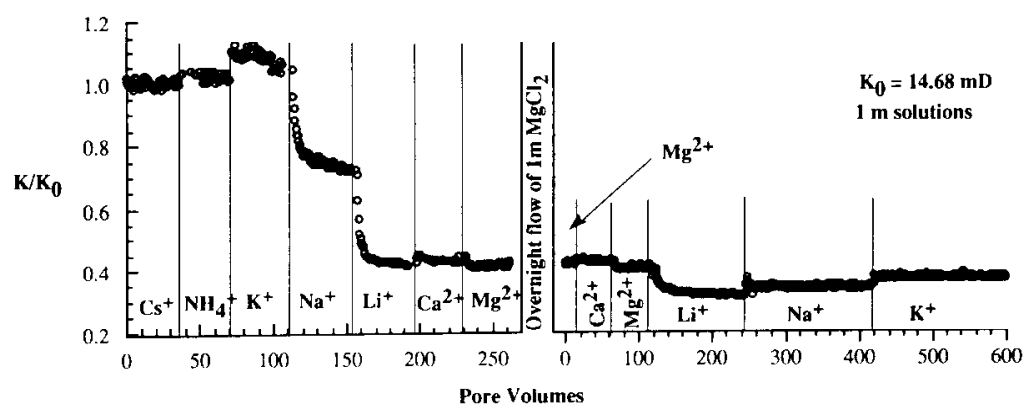

Fig. 10. Irreversibility of damage induced by crystalline swelling in Stevens sandstone. 


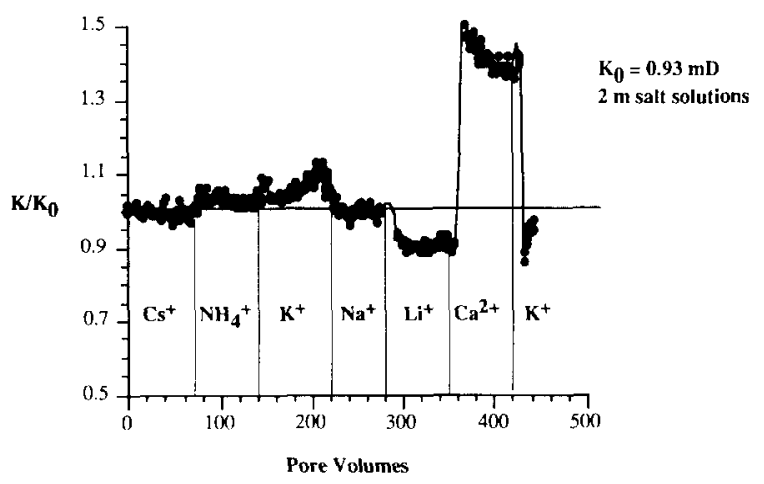

Fig. 11. Permeability response of Stevens sandstone subjected to flow of solutions containing cations of increasing radius of hydration at 2 molal.

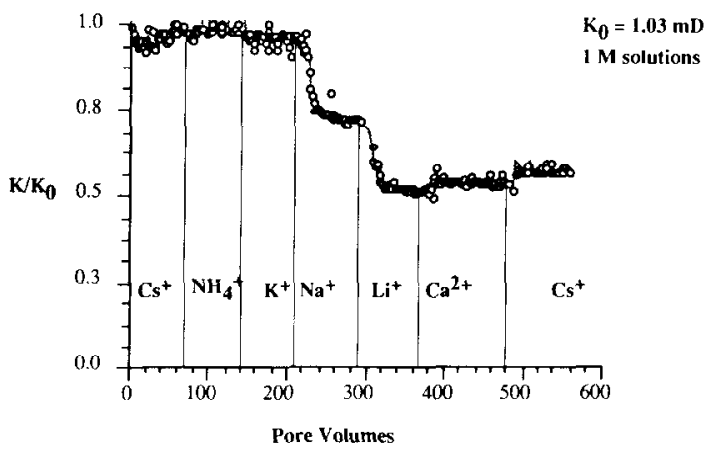

Fig. 12. Permeability response of Stevens sandstone subjected to flow of solutions containing cations of increasing radius of hydration at I $M$.

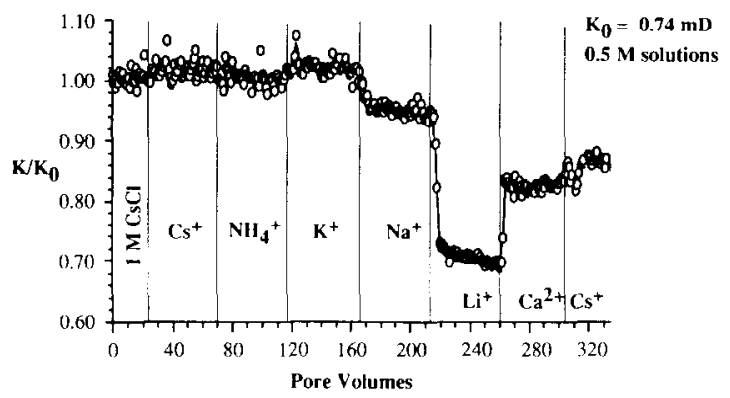

Fig. 13. Permeability response of Stevens sandstone subjected to flow of solutions containing cations of increasing radius of hydration at $0.5 \mathrm{M}$

damage, but switching from sodium to lithium caused significant damage. It should be noted that montmorillonites disperse more readily in lithium solutions compared to sodium. Therefore the damage due to lithium at $0.5 \mathrm{M}$ may be due to dispersion. However, the results of the three experiments clearly show lesser damage between sodium and potassium at higher concentrations. Additionally, the damage between sodium and lithium is higher at $1 M$ than at 2 molal. The results indicate that as the concentration increases the damage due to exchange of ions of increasing radius of hydration decreases, which is consistent with the hypothesis that the swelling that induces the movement is in the crystalline regime. In order to substantiate further these results, we need information on the crystalline swelling of smectites/ mixed layer clays specifically present in the Stevens sandstones. This work is currently underway.

In summary, the results of the cation-specific experiments show that swelling-induced migration is a significant mechanism of damage in swelling clay sandstones. The clay swelling for these experiments occurs in the crystalline swelling regime.

\section{Discussion}

The water sensitivity of natural sandstones which contain a range of clays is strongly dependent on the clay composition as well as the distribution. The experimental results for Stevens sandstone compared to Berea sandstone illustrate this point. Ideally, the water sensitivity of a sandstone should be tested by performing experiments similar to those described in this paper. However, a priori estimates on water sensitivity can be obtained by a careful analysis of the mechanisms of damage in conjunction with the mineralogical composition and lithology of the sandstone. It has to be recognized that flow tests are very time consuming and an understanding of the mechanisms of damage is essential for efficient experimental design.

The analysis of the mechanisms by which nonswelling clays (e.g. kaolinite) cause damage has been described by Khilar [5]. The forces of interaction between the clay particle and the rock surface are the van der Waals attraction, the electrostatic repulsion, and at close separations the Born repulsion [5,7,29]. Recent evidence shows 
that the water structure between surfaces causes additional repulsive force $[30,31]$. By considering these forces, one can construct total interaction potential curves between the rock surface and the clay particle and determine the ionic concentration and $\mathrm{pH}$ at which the interaction becomes repulsive, allowing particles to be released from the surface. This type of analysis has been shown to describe adequately the release of kaolinite particles in Berea sandstone [5-7]. Thus, it is possible to predict the conditions for release of non-swelling particles based on the electrochemical properties of the particles and the surface.

The experimental results described in this paper have shown that swelling clays contribute significantly to the total damage of Stevens sandstone. An understanding of the mechanisms by which swelling clays reduce permeability is essential to relate the permeability loss caused by these clays to changes in aqueous composition. As mentioned earlier, swelling clays can cause permeability loss by reducing pore cross-sectional area, by causing other fines to move (swelling-induced migration) and by dispersion. The basal spacing measurement is indicative of the swelling state of the particles. The swelling behavior of smectites is dependent on the charge and the interlayer cations, among other variables. As described previously, XRD measurements using low charged smectites immersed in sodium chloride solutions of different concentrations show that the spacing increases in discrete steps with decreasing concentration and jumps suddenly to a high spacing in the osmotic regime. The concentration at which this transition to the osmotic region occurs is dependent on the charge of the smectites. Sodium saturated forms of highly charged smectites such as Nibost and Drayton do not expand even in distilled water [24]. However, the lithium forms of these smectites readily swell and disperse in deionized water. From a formation damage standpoint, both the crystalline swelling and the transition from crystalline swelling to osmotic swelling are important. The transition from crystalline to osmotic swelling regime is indicative of dispersion and irreversible permeability loss. Crystalline swelling can cause damage by reduction of pore cross-sectional area for flow and by inducing movement in other fines as demonstrated in Stevens sandstone. In order to relate the permeability reduction due to changes in aqueous composition to the crystalline and osmotic domains of swelling and the transition between the swelling domains, it is necessary to understand the underlying forces governing these processes.

In the past, crystalline swelling has been analyzed as a result of the balance between the repulsive hydration energy of cations, and the electrostatic attractive forces between cations and the negatively charged plates $[23,24]$. These two factors can explain limited swelling in highly charged smectites and the dependence of basal spacing on the type of cation in a qualitative manner. However, this analysis does not account for the sudden transition between crystalline swelling and osmotic swelling and cannot provide quantitative correlation of permeability changes to basal spacing measurements. Additional forces which are presumed to affect the crystalline swelling include forces responsible for surface hydration (dispersion and hydrogen bonding), van der Waals and Born repulsion between clay layers [32].

Osmotic swelling has traditionally been described using double layer theory $[17,23]$. In this region, the clay can be considered as being dispersed and the spacings between dispersed particles are related to the electrostatic repulsion between charged clay surfaces and the van der Waals attractive forces. In view of the fact that most of the charge in smectites is due to isomorphic substitution, the clay surfaces have typically been considered as constant charge surfaccs. However, zeta potential measurements on montmorillonites show that these particles exhibit constant surface potential behavior, indicating significant rearrangement of ions in the Stern layer [33]. It should also be noted that the classical DLVO theory cannot account for high repulsive pressures observed at close separations in clay dispersions which are dependent on the nature of cations [32].

The excess repulsive pressures at close separa- 
tions have been attributed to the water structure next to the layers similar to the concentrationdependent hydration forces observed between mica surfaces $[31,32]$. 'This explanation can account for the cation-specific nature of these repulsive pressures. However, it has also been shown that high repulsive pressures at close separations in clay dispersions can be explained using an ionic adsorption model [34]. In this model the counterions are assumed to be adsorbed in two layers (hydrated and dehydrated) and the equilibrium between these layers is dependent on the concentration of the cations. The quantitative agreement of repulsive pressure data with the ionic adsorption model implies that the modified water structure theory need not be invoked to account for repulsive deviations from DLVO predictions. A recent theory which accounts for the interactions in dispersed systems is based on AB (acid-base) forces which account for the polar and hydrogen bonding interactions between the surfaces and the liquid [35]. This model has been shown to predict the stability of hectorite dispersions in sodium chloride solutions adequately. However, the short-range $\mathrm{AB}$ force used to describe the stability of hectorite dispersion is an attractive one. Conversely, the surface force and swelling pressure measurements confirm the existence of a short-range non-DLVO repulsive force. Thus the nature and magnitude of the short-range force as well as how it is affected by solution conditions is at present not fully understood.

In view of the above discussion, one can infer that a quantitative theoretical explanation of the crystalline swelling and transition from crystalline to osmotic swclling is currently not possible owing to lack of a complete understanding of the forces involved. This issue will be addressed further in a future paper. The osmotic swelling region is relatively easier to describe theoretically because the forces involved in this process are better understood. However, the osmotic swelling region for sandstones containing swelling and non-swelling clays corresponds to the same regime in which non-swelling clays such as illites start contributing to permeability reduction. In addition, some of the permeability reduction in the transition regime and in the osmotic regime is caused by movement of fines induced by swelling. I hus, in natural sandstones a quantitative description of permeability change in the osmotic swelling regime has to include factors that take lithology and hydrodynamics into account and is not addressed in this paper.

The mechanism of permeability reduction due to swelling-induced fines migration assumes that the swelling clays occur in such a fashion that when they swell they cause the detachment of other particles. The detached particles could be other minerals and certainly may include clays as well. The occurrence of clays in this form can be proved by examining scanning electron micrographs of a Temblor Sand, Coalinga field, which is primarily smectitic and exhibits crystalline swelling similar to Stevens sandstone. Conventional scanning electron microscopy sample preparation procedures cannot be used to examine the morphology of clays in natural porous media because they can alter the clay structure $[36,37]$. A technique to prevent such morphological changes is the critical point drying method [36,37]. The micrographs of critical point dried samples on Temblor sandstone at two magnifications are shown in Fig. 14. The figures show the quartz grains covered by leaf-like smectitic clays connected with ribbon-like illite clays. It is conceivable that when the smectites expand, they impose stresses sufficient to break the illites or other smectite particles. The morphology of clays in Stevens sandstone is being currently investigated using critical point dried samples. It has to be pointed out that our results do not imply that crystalline swelling in all smectitic rocks causes migration. This property is indeed expected to be dependent on the depositionary environment.

\section{Conclusions}

Swelling clays contribute significantly to water sensitivity of Stevens sandstones which contain 

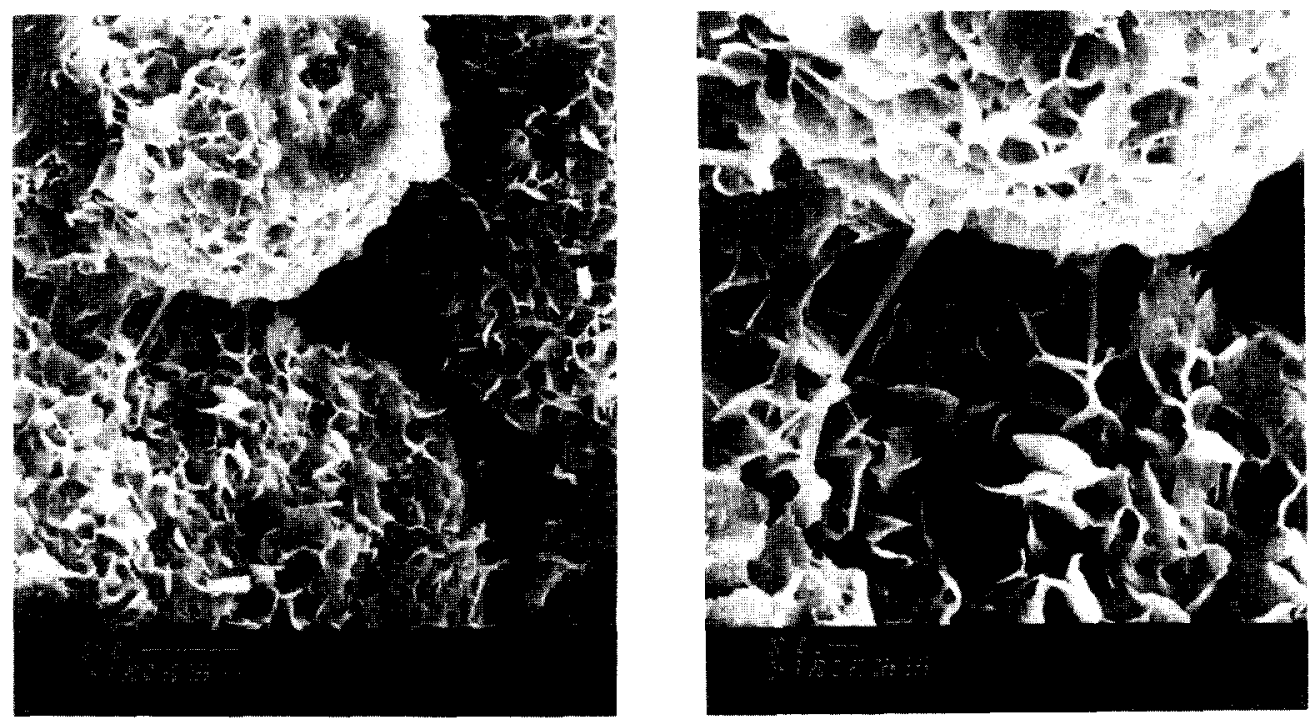

Fig. 14. Scanning electron micrographs of critical point dried samples from Temblor Sands showing sand grains with smectites and illites.

swelling as well as non-swelling clays. The critical salt concentration values of sodium chloride, potassium chloride and calcium chloride needed to prevent loss of permeability in these sandstones are considerably higher than those of Berea sandstone which contains primarily non-swelling clays. The rate of salinity decrease and the low injection $\mathrm{pH}$ have only a marginal effect in controlling the permeability reduction in Stevens sandstones, suggesting that $\mathrm{pH}$ control does not eliminate or affect the mechanisms that cause permeability loss. Movement of fines or clays induced by structural expansion of smectites/mixed layer clays in the crystalline region is shown to result in considerable permeability reduction of Stevens sandstones.

\section{Acknowledgments}

The authors gratefully acknowledge Greg S. Orton for coring the Stevens sandstone samples and Sharon J. Puckett for coring the samples and performing the scanning electron microscopy analysis of critical point dried Temblor Sands samples. The authors acknowledge the financial support of the sponsors of the Industrial Affiliates Program at the University of Michigan.

\section{References}

N. Mungan, J. Pet. Technol., 17 (1965) 1449.

2 A. Lever and R.A. Dawe, J. Pet. Geol., 7 (1984) 97.

3 D.H. Gray and R.W. Rex, Clays Clay Miner., 14 (1966) 355.

4 F.O. Jones, J. Pet. Technol., 16 (1964) 441.

5 K.C. Khilar, Ph.D. Dissertation, University of Michigan, MI, 1981

6 S.F. Kia, H.S. Fogler, M.G. Reed and R.N. Vaidya, SPE Prod. Eng., 2 (1987) 277.

7 R.N. Vaidya, Ph.D. Dissertation, University of Michigan, MI, 1991

8 J.A. Leone and M.E. Scott, SPE Reservoir Eng., 3 (1988) 1279.

9 R.F. Scheurman and B.M. Bergersen, Paper SPE 18461 presented at the 1989 SPE Int. Symp. on Oilfield Chemistry, Houston, February 8-10.

10 H. Frenkel, J.O. Goertzen and J.D. Rhoades, Soil Sci. Soc. Am. J., 42 (1978) 32.

11 D.L. Suarez, J.D. Rhoades, R. Lavado and C.M. Grieve, Soil Sci. Soc. Am. J., 48 (1984) 50.

12 I. Shainberg, R. Keren, N. Alpertovich and D. Goldstein, Clays Clay Miner., 35 (1987) 305.

13 N. Alpertovich, I. Shainherg and R. Keren, Clays Clay Miner., 33 (1985) 443.

14 L.C. Goldenberg, M. Magaritz, A.J. Amiel and S. Mandel, J. Hydrol., 70 (1984) 329.

15 B.L. MeNeal, D.A. Layfield, W.A. Norvell and J.D. Rhoades, Soil Sci. Soc. Am. J., 32 (1968) 187.

16 J.H. Hardcastle and J.K. Mitchell, Clays Clay Miner., 22 (1974) 143

17 J.P. Quirk and R.K. Schofield, J. Soil Sci., 6 (1955) 163

18 P.B. Basan, Paper SPE 14317 presented at the Annual 
Technical Conference and Exhibition, Dallas, September 22 25, 1985.

19 L.M. McDowell-Boyer, Environ. Sci. Technol, 26 (1992) 586.

20 K.C. Khilar, H.S. Fogler and D.H. Gray, J. Geotech. Eng. Div. ASCE, 111 (1985) 833.

$21 \mathrm{H}$. van Olphen, An Introduction to Clay Colloid Chemistry, Wiley, New York, 1977.

22 R.L. Churcher, P.R. French, J.C. Shaw and L.L. Schramm, Paper SPE 21041 presented at the 1991 Int. Symp. on Oilfield Chemistry, Anaheim, February 20-22.

23 K. Norrish, Faraday Soc. Discuss., 18 (1954) 120.

24 P.G. Slade, I.P. Quirk and K. Norrish, Clays Clay Miner., 39 (1991) 234

25 A.M. Posner and J.P. Quirk, J. Colloid Sci., 19 (1964) 788.

26 P.G. Slade and J.P. Quirk, J. Colloid Interface Sci., 144 (1991) 18 .

27 E. Tombacz, I. Abraham, M. Gilde and F. Szanto, Colloids Surfaces, 49 (1990) 71 .
28 S. Goldberg, H.S. Forster and E.L. Heick, Clays Clay Miner., 39 (1991) 375.

29 D.C. Prieve and E. Ruckenstein, Am. Inst. Chem. Eng. J., 22 (1978) 1145.

30 J.N. Israelachvili, Adv. Colloid Interface Sci., 16 (1982) 31.

31 R.M. Pashley and J.P. Quirk, Colloids Surfaces, 9 (1984) 1.

32 Y. Horikawa, R.S. Murray and J.P. Quirk, Colloids Surfaces, 32 (1988) 181.

33 P.F. Low, Langmuir, 3 (1987) 18.

34 J.J. Spitzer, Langmuir, 5 (1989) 199.

35 C.J. van Oss, R.F. Giese and P.M. Costanzo, Clays Clay Miner., 38 (1990) 151.

36 N. Pallat, J. Wilson and B. McHardy, J. Pet. Technol., 36 (1984) 2225.

37 M.G. Reed, Presented at the 1987 Annual Meeting of Socicty of Corc Analysts, Houston, TX.

38 R.E. Grim, Clay Mineralogy, McGraw-Hill, Englewood Cliffs, NJ, 1968. 